\title{
Multiple antimicrobial resistance and outcomes among hospitalized patients with complicated urinary tract infections in the US, 2013-2018: a retrospective cohort study
}

\author{
Marya D. Zilberberg ${ }^{1 *}\left(\mathbb{D}\right.$, Brian H. Nathanson ${ }^{2}$, Kate Sulham ${ }^{3}$ and Andrew F. Shorr ${ }^{4}$
}

\begin{abstract}
Background: Complicated urinary tract infection (cUTI) is common among hospitalized patients. Though carbapenems are an effective treatment in the face of rising resistance, overuse drives carbapenem resistance (CR). We hypothesized that resistance to routinely used antimicrobials is common, and, despite frequent use of carbapenems, associated with an increased risk of inappropriate empiric treatment (IET), which in turn worsens clinical outcomes.

Methods: We conducted a retrospective cohort study of patients hospitalized with a culture-positive non-CR cUTI. Triple resistance (TR) was defined as resistance to $\geq 3$ of the following: 3rd generation cephalosporins, fluoroquinolones, trimethoprim-sulfamethoxazole, fosfomycin, and nitrofurantoin. Multivariable models quantified the impact of TR and inappropriate empiric therapy (IET) on mortality, hospital LOS, and costs.

Results: Among 23,331 patients with CUTI, 3040 (13.0\%) had a TR pathogen. Compared to patients with non-TR, those with TR were more likely male $(57.6 \%$ vs. $47.7 \%, p<0.001)$, black $(17.9 \%$ vs. $13.6 \%, p<0.001)$, and in the South (46.3\% vs. 41.5\%, $p$ <.001). Patients with TR had higher chronic (median [IQR] Charlson score $3[2,4]$ vs. $2[1,4]$, $p<0.001$ ) and acute (mechanical ventilation $7.0 \%$ vs. $5.0 \%, p<0.001$; ICU admission $22.3 \%$ vs. $18.6 \%, p<0.001$ ) disease burden. Despite greater prevalence of empiric carbapenem exposure ( $43.3 \%$ vs. $16.2 \%, p<0.001)$, patient with TR were also more likely to receive IET $(19.6 \%$ vs. $5.4 \%, p<0.001)$ than those with non-TR. Although mortality was similar between groups, TR added $0.38(95 \% \mathrm{Cl} 0.18,0.49)$ days to LOS, and $\$ 754(95 \% \mathrm{Cl} \$ 406, \$ 1103)$ to hospital costs. Both TR and IET impacted the outcomes among CUTI patients whose UTI was not catheterassociated (CAUTI), but had no effect on outcomes in CAUTI.

Conclusions: TR occurs in 1 in 8 patients hospitalized with CUTI. It is associated with an increase in the risk of IET exposure, as well as a modest attributable prolongation of LOS and increase in total costs, particularly in the setting of non-CAUTI.
\end{abstract}

Keywords: Complicated UTI, Antimicrobial resistance, Epidemiology, Microbiology, Outcomes, Hospitalization

\footnotetext{
* Correspondence: evimedgroup@gmail.com

${ }^{1}$ EviMed Research Group, LLC, PO Box 303, Goshen, MA 01032, USA

Full list of author information is available at the end of the article
}

C C The Author(s). 2021 Open Access This article is licensed under a Creative Commons Attribution 4.0 International License, which permits use, sharing, adaptation, distribution and reproduction in any medium or format, as long as you give appropriate credit to the original author(s) and the source, provide a link to the Creative Commons licence, and indicate if changes were made. The images or other third party material in this article are included in the article's Creative Commons licence, unless indicated otherwise in a credit line to the material. If material is not included in the article's Creative Commons licence and your intended use is not permitted by statutory regulation or exceeds the permitted use, you will need to obtain permission directly from the copyright holder. To view a copy of this licence, visit http://creativecommons.org/licenses/by/4.0/. The Creative Commons Public Domain Dedication waiver (http://creativecommons.org/publicdomain/zero/1.0/) applies to the data made available in this article, unless otherwise stated in a credit line to the data. 


\section{Background}

Complicated urinary tract infections (cUTI) are a leading infection-related reason for acute hospitalization. A cUTI can also arise as a nosocomial complication that represents a key focus for prevention among hospitalized patients. Frequently occurring in the presence of an indwelling catheter, catheter-associated urinary tract infections (CAUTIs) are the publicly reportable subset of cUTI, and are included in the Hospital Compare metrics by the United States Centers for Medicare and Medicaid Services $[1,2]$. Irrespective of whether community- (CO) or hospital-onset (HO), cUTIs place a significant burden on the healthcare system.

Rising rates of antimicrobial resistance to commonly used antibiotics are adding hurdles to patient care [3]. Particularly troubling is the growing prevalence of extended-spectrum beta-lactamase producing Enterobacteraciae (ESBLs) at the time that the in vitro susceptibility rates to fluroquinolones and other routinely employed antimicrobials for cUTI, such as 3rd generation cephalosporins and trimethoprim-sulfamethoxazole, are diminishing [4-7]. These shifts are making it difficult for clinicians to target empiric therapy.

In order to weigh the risks of therapeutic failure when administering standard treatment regimens, we examined the prevalence of overlapping resistance to commonly utilized antibiotics in cUTI and its impact on the outcomes. We also estimated the rate of inappropriate empiric therapy (IET) as a function of compound resistance in cUTI, and of its impact on morbidity and mortality.

\section{Methods}

\section{Ethics statement}

Because this study used already existing fully de-identified data, it was exempt from ethics review under US 45 CFR 46.101(b)4 [8, 9]. Current analyses were performed within the same cohort of patients as those reported in citation 10 .

\section{Study design and patient population}

We conducted a multi-center retrospective cohort study of hospitalized patients with culture-positive carbapenemsusceptible cUTI to explore the prevalence and impact of resistance to commonly used non-carbapenem empiric regimens. The case identification approach relied on a previously published algorithm [10].

The cohort was followed longitudinally until discharge or death in the hospital. Survivors were followed for additional 30 days for the outcome of 30-day readmission.

\section{Data source}

The data for the study derived from Premier Research database, an electronic laboratory, pharmacy and billing data repository, for years 2013 through 2018. The database has been described in detail previously [9-13]. We used data from a subset of approximately 180 US institutions who submitted microbiology data during the study time frame.

\section{Baseline measures and cUTI classification}

cUTI was classified as $\mathrm{CO}$ if present on admission (POA) or if index culture was drawn within first 2 hospital days. CO cUTI was further classified as healthcareassociated (HCA) if one or more of the following risk factors was present: 1). Hospitalization within prior 90 days, 2). Hemodialysis, 3). Admission from a long-term care facility, 4). Immune suppression [10]. All other CO infections were community-acquired (CA). All cUTIs occurring on or after hospital day 3 were considered $\mathrm{HO}$.

In addition to infection classification, patient factors examined included history of exposure to antibiotics within prior 90 days; antibiotics exposure during the index hospitalization prior to cUTI onset if $\mathrm{HO}$; previous Emergency Department visit with a UTI within 90 days of the index culture; hospital structural characteristics (size, teaching status, urbanicity, census region); demographic variables, and comorbid conditions. Charlson comorbidity score was computed as a measure of the burden of chronic illness.

\section{Infection and treatment variables}

ICU admission, mechanical ventilation, presence of severe sepsis or septic shock, dialysis, and vasopressor use were used as markers for acute disease severity. Organisms and their susceptibilities were identified, and empiric antibiotic treatment was considered appropriate if the patient received coverage that included the corresponding organism within two days of the culture being obtained. All other coverage was considered IET.

\section{Microbiology and susceptibilities}

Organisms were classified as susceptible (S), intermediate (I), or resistant (R). For the purposes of the current analyses, I and $\mathrm{R}$ were grouped together as resistant. We determined each isolate's susceptibility status to each of the common antimicrobials of interest (3rd generation cephalosporins, [C3]; fluoroquinolones [FQ]; trimethoprim-sulfamethoxazole [TMP-SMZ]; fosfomycin [FFM]; and nitrofurantoin [NTF]). Triple-drug resistance (TR) was defined as resistance to at least three separate antimicrobials or classes of interest (i.e., resistance to at least one of the member drugs within the class).

First detection of an organism served as the index culture. To be considered culture-positive, the patient had to grow out a qualifying common bacterium in urine or blood. Organisms of interest included Enterobacteriaceae, P. aeruginosa, A. baumannii, E. faecium, E. faecalis [9]. 


\section{Outcome variables}

Hospital mortality served as the primary outcome, and 30-day readmission, hospital length of stay (LOS) and costs as secondary outcomes. Exploratory outcomes were incidence of $C$. difficile infection (CDI), cUTI recurrence (defined as a new positive culture following a $>/=3$-day hiatus in antimicrobial administration), and development of TR. All antimicrobial susceptibility testing was done at the individual hospital in accordance with its standards and consistent with in vitro breakpoints in place at the time.

\section{Statistical analyses}

We report standard descriptive statistics to compare TR and non-TR groups across all demographics, comorbidities, infection characteristics, hospital characteristics and processes, and hospital outcomes. Continuous variables are reported as means with standard deviations and as medians with interquartile ranges (IQR). Differences between mean values were tested via Student's t-test, and between medians using the Mann-Whitney $U$ test. Categorical data are summarized as proportions, with the Chi-square or Fisher's exact test used to examine inter-group differences. Statistical significance was set at $p<0.05$. Because of the large sample size, statistical significance may not equate to clinical significance.

We developed multilevel mixed-effects regression models to examine the impact of TR on hospital outcomes with hospitals treated as random effects. For continuous variables (LOS and costs), we used generalized linear models with a gamma distribution, and applied a logarithmic link function. For categorical variables (mortality, 30-day readmission, recurrence, incident TR and CDI), we used logistic regression. We bracketed the point estimates with 95\% confidence intervals (CI).

\section{Results}

Among 23,331 patients with cUTI who met the enrollment criteria 28,192 organisms were isolated [9]. The pathogens, TR prevalence over the study timeframe, and resistance rates to individual antimicrobials are in Table 1, Supplemental Table 1, as well as in the Supplemental Table 4 in citation 10. The prevalence of TR in the cohort was $13.0 \%$ ( $n=3040$, Table 2). Compared to patients with non-TR, those with TR were more likely male $(57.6 \%$ vs. $47.7 \%, p<0.001)$, black (17.9\% vs. $13.6 \%, p<0.001)$, and in the South $(46.3 \%$ vs. $41.5 \%, \mathrm{p}<0.001)$, and had a higher chronic disease burden (median [IQR] Charlson score 3

Table 1 Microbiology of CUTI

\begin{tabular}{|c|c|c|c|c|c|c|}
\hline & TR & $\%$ & non-TR & $\%$ & All & $\%^{a}$ \\
\hline & $N=3040$ & & $N=20,291$ & & $N=23,331$ & \\
\hline \multicolumn{7}{|l|}{ Organism } \\
\hline Escherichia coli & 1470 & $48.36 \%$ & 10,040 & $49.48 \%$ & 11,510 & $49.33 \%$ \\
\hline Klebsiella pneumoniae & 530 & $17.43 \%$ & 2865 & $14.12 \%$ & 3395 & $14.55 \%$ \\
\hline Pseudomonas aeruginosa & 244 & $8.03 \%$ & 2836 & $13.98 \%$ & 3080 & $13.20 \%$ \\
\hline Proteus mirabilis & 916 & $30.13 \%$ & 1823 & $8.98 \%$ & 2739 & $11.74 \%$ \\
\hline Enterococcus faecalis & 195 & $6.41 \%$ & 2251 & $11.09 \%$ & 2446 & $10.48 \%$ \\
\hline Enterococcus spp. & 80 & $2.63 \%$ & 856 & $4.22 \%$ & 936 & $4.01 \%$ \\
\hline Enterobacter cloacae & 118 & $3.88 \%$ & 547 & $2.70 \%$ & 665 & $2.85 \%$ \\
\hline Klebsiella oxytoca & 32 & $1.05 \%$ & 469 & $2.31 \%$ & 501 & $2.15 \%$ \\
\hline Providencia spp & 133 & $4.38 \%$ & 340 & $1.68 \%$ & 473 & $2.03 \%$ \\
\hline Citrobacter freundii & 40 & $1.32 \%$ & 393 & $1.94 \%$ & 433 & $1.86 \%$ \\
\hline Morganella morganii & 173 & $5.69 \%$ & 229 & $1.13 \%$ & 402 & $1.72 \%$ \\
\hline Serratia marcescens & 39 & $1.28 \%$ & 321 & $1.58 \%$ & 360 & $1.54 \%$ \\
\hline Enterococcus faecium & 27 & $0.89 \%$ & 312 & $1.54 \%$ & 339 & $1.45 \%$ \\
\hline Enterobacter aerogenes & 8 & $0.26 \%$ & 276 & $1.36 \%$ & 284 & $1.22 \%$ \\
\hline Citrobacter spp. & 17 & $0.56 \%$ & 223 & $1.10 \%$ & 240 & $1.03 \%$ \\
\hline Acinetobacter baumannii & 25 & $0.82 \%$ & 125 & $0.62 \%$ & 150 & $0.64 \%$ \\
\hline Proteus spp. & 16 & $0.53 \%$ & 103 & $0.51 \%$ & 119 & $0.51 \%$ \\
\hline Enterobacter spp. & 3 & $0.10 \%$ & 43 & $0.21 \%$ & 46 & $0.20 \%$ \\
\hline Klebsiella spp. & 6 & $0.20 \%$ & 33 & $0.16 \%$ & 39 & $0.17 \%$ \\
\hline Serratia spp. & 6 & $0.20 \%$ & 29 & $0.14 \%$ & 35 & $0.15 \%$ \\
\hline
\end{tabular}

cUTI complicated urinary tract infection, TR triple resistant

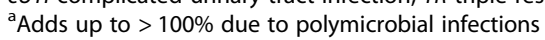


Table 2 Baseline characteristics

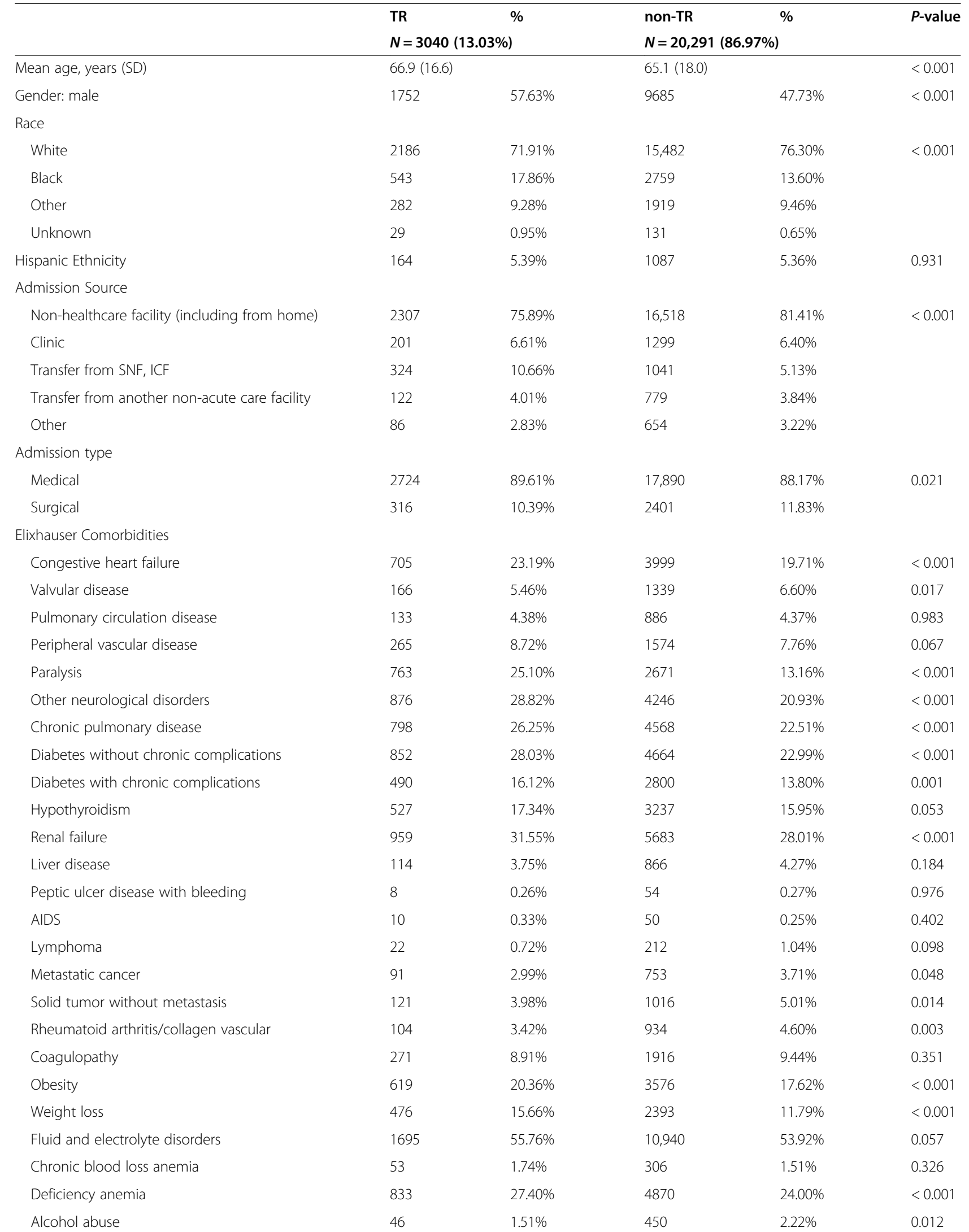


Table 2 Baseline characteristics (Continued)

\begin{tabular}{|c|c|c|c|c|c|}
\hline \multirow{3}{*}{ Drug abuse } & TR & $\%$ & non-TR & $\%$ & $P$-value \\
\hline & \multicolumn{2}{|c|}{$N=3040(13.03 \%)$} & \multicolumn{3}{|c|}{$N=20,291(86.97 \%)$} \\
\hline & 88 & $2.89 \%$ & 655 & $3.23 \%$ & 0.329 \\
\hline Psychosis & 139 & $4.57 \%$ & 801 & $3.95 \%$ & 0.102 \\
\hline Depression & 635 & $20.89 \%$ & 3454 & $17.02 \%$ & $<0.001$ \\
\hline Hypertension & 2063 & $67.86 \%$ & 13,378 & $65.93 \%$ & 0.036 \\
\hline \multicolumn{6}{|c|}{ Charlson Comoribidity Score } \\
\hline 0 & 344 & $11.32 \%$ & 4046 & $19.94 \%$ & \multirow[t]{6}{*}{$<0.001$} \\
\hline 1 & 413 & $13.59 \%$ & 3534 & $17.42 \%$ & \\
\hline 2 & 669 & $22.01 \%$ & 3893 & $19.19 \%$ & \\
\hline 3 & 517 & $17.01 \%$ & 3052 & $15.04 \%$ & \\
\hline 4 & 375 & $12.34 \%$ & 2069 & $10.20 \%$ & \\
\hline $5+$ & 722 & $23.75 \%$ & 3697 & $18.22 \%$ & \\
\hline Mean (SD) & \multicolumn{2}{|c|}{$3.1(2.3)$} & \multicolumn{2}{|l|}{$2.6(2.4)$} & $<0.001$ \\
\hline Median [IQR] & \multicolumn{2}{|l|}{$3[2,4]$} & \multicolumn{2}{|l|}{$2[1,4]$} & $<0.001$ \\
\hline \multicolumn{6}{|c|}{ Hospital Characteristics } \\
\hline \multicolumn{6}{|l|}{ Census region } \\
\hline Midwest & 956 & $31.45 \%$ & 6829 & $33.66 \%$ & \multirow[t]{4}{*}{$<0.001$} \\
\hline Northeast & 370 & $12.17 \%$ & 2653 & $13.07 \%$ & \\
\hline South & 1406 & $46.25 \%$ & 8412 & $41.46 \%$ & \\
\hline West & 308 & $10.13 \%$ & 2397 & $11.81 \%$ & \\
\hline \multicolumn{6}{|l|}{ Number of Beds } \\
\hline$<100$ & 121 & $3.98 \%$ & 1010 & $4.98 \%$ & \\
\hline 100 to 199 & 373 & $12.27 \%$ & 2623 & $12.93 \%$ & \multirow[t]{5}{*}{0.001} \\
\hline 200 to 299 & 667 & $21.94 \%$ & 4138 & $20.39 \%$ & \\
\hline 300 to 399 & 524 & $17.24 \%$ & 3051 & $15.04 \%$ & \\
\hline 400 to 499 & 504 & $16.58 \%$ & 3567 & $17.58 \%$ & \\
\hline $500+$ & 851 & $27.99 \%$ & 5902 & $29.09 \%$ & \\
\hline Teaching & 1258 & $41.38 \%$ & 8482 & $41.80 \%$ & 0.661 \\
\hline Urban & 2623 & $86.28 \%$ & 17,599 & $86.73 \%$ & 0.815 \\
\hline \multicolumn{6}{|c|}{ C3R Rate at Hospital Level } \\
\hline Mean (SD) & \multicolumn{2}{|c|}{$17.0 \%(7.6 \%)$} & \multicolumn{2}{|c|}{$14.8 \%(6.8 \%)$} & $<0.001$ \\
\hline Median [IQR] & \multicolumn{2}{|c|}{$16.3 \%[12.4,20.9 \%]$} & \multicolumn{2}{|c|}{$14.4 \%[10.2,17.7 \%]$} & $<0.001$ \\
\hline \multicolumn{6}{|c|}{ TR Rate at Hospital Level } \\
\hline Mean (SD) & \multicolumn{2}{|c|}{$15.7 \%(6.4 \%)$} & \multicolumn{2}{|c|}{$12.6 \%(5.7 \%)$} & $<0.001$ \\
\hline Median [IQR] & \multicolumn{2}{|c|}{$15.1 \%[11.3,18.8 \%]$} & \multicolumn{2}{|c|}{$12.2 \%[9.4,16.1 \%]$} & $<0.001$ \\
\hline
\end{tabular}

$M D R$ multidrug resistant, $S D$ standard deviation, SNF skilled nursing facility, ICF intermediate care facility, AIDS acquired immune deficiency syndrome, IQR interquartile range, $C 3 R$ 3rd generation cephalosporin-resistant, $C R$ carbapenem resistant

$[2,4]$ vs. $2[1,4], \mathrm{p}<0.001)$. Patients with TR were hospitalized at centers with higher median prevalence of both C3R and TR (Table 2).

TR was associated with increase in some illness severity markers relative to non-TR (need for MV and ICU), though others were similar between the two groups (Table 3). Though the majority of all infections were monomicrobial (71.8\% TR vs. $84.4 \%$ non-TR), patients with TR were more likely to have a polymicrobial cUTI. Similarly, while $>95 \%$ of all cUTI was CO, HCA cUTI was more common in TR patients than among non-TR (49.5\% vs. $36.2 \%, p<0.001)$. Consequently, more patients with TR had experienced a hospitalization and antimicrobial treatment within 90 days prior to the index hospitalization, and had within the same time period an isolate exhibiting resistance to one of the antibiotics or 
Table 3 Infection and treatment characteristics

\begin{tabular}{|c|c|c|c|c|c|}
\hline & TR & $\%$ & non-TR & $\%$ & $P$-value \\
\hline & \multicolumn{2}{|l|}{$N=3040$} & \multicolumn{3}{|c|}{$N=20,291$} \\
\hline \multicolumn{6}{|l|}{ Infection } \\
\hline \multicolumn{6}{|l|}{ Illness severity measures by day 2 from onset } \\
\hline ICU admission & 677 & $22.27 \%$ & 3774 & $18.60 \%$ & $<0.001$ \\
\hline Mechanical ventilation & 213 & $7.01 \%$ & 1012 & $4.99 \%$ & $<0.001$ \\
\hline Vasopressors & 183 & $6.02 \%$ & 1333 & $6.57 \%$ & 0.252 \\
\hline Dialysis & 68 & $2.24 \%$ & 389 & $1.92 \%$ & 0.235 \\
\hline Severe sepsis & 537 & $17.66 \%$ & 3549 & $17.49 \%$ & 0.814 \\
\hline Severe sepsis POA & 523 & $17.20 \%$ & 3382 & $16.67 \%$ & 0.460 \\
\hline Septic shock & 386 & $12.70 \%$ & 2274 & $11.21 \%$ & 0.016 \\
\hline Septic shock POA & 360 & $11.84 \%$ & 2049 & $10.10 \%$ & 0.003 \\
\hline Monomicrobial & 2184 & $71.84 \%$ & 17,115 & $84.35 \%$ & $<0.001$ \\
\hline \multicolumn{6}{|l|}{ Polymicrobial } \\
\hline 2 organisms & 758 & $24.93 \%$ & 2837 & $13.98 \%$ & $<0.001$ \\
\hline 3 or more organisms & 98 & $3.22 \%$ & 339 & $1.67 \%$ & \\
\hline \multicolumn{6}{|l|}{ Infection characteristics } \\
\hline Community-onset & 2970 & $97.70 \%$ & 19,472 & $95.96 \%$ & $<0.001$ \\
\hline Community-acquired & 1465 & $48.19 \%$ & 12,134 & $59.80 \%$ & \\
\hline Healthcare-associated & 1505 & $49.51 \%$ & 7338 & $36.16 \%$ & \\
\hline Hospital-onset & 70 & $2.30 \%$ & 819 & $4.04 \%$ & $<0.001$ \\
\hline \multicolumn{6}{|l|}{ Type of cUTI } \\
\hline CAUTI & 747 & $24.57 \%$ & 8984 & $44.28 \%$ & \\
\hline non-CAUTI-cUTI & 2293 & $75.43 \%$ & 11,307 & $55.72 \%$ & $<0.001$ \\
\hline \multicolumn{6}{|l|}{ Culture source } \\
\hline Blood only & 12 & $0.39 \%$ & 138 & $0.68 \%$ & \\
\hline Urine only & 917 & $30.16 \%$ & 6321 & $31.15 \%$ & 0.090 \\
\hline Blood and urine & 2111 & $69.44 \%$ & 13,832 & $68.17 \%$ & \\
\hline \multicolumn{6}{|l|}{ Time to CUTI } \\
\hline Mean (SD) & $1.3(2.3)$ & & $1.5(3.0)$ & & 0.002 \\
\hline Median [IQR] & $1[1,1]$ & & $1[1,1]$ & & $<0.001$ \\
\hline Prior hospitalization within 90 days & 1250 & $41.12 \%$ & 6074 & $29.93 \%$ & $<0.001$ \\
\hline Antibiotics within 90 days prior to admission & 1101 & $36.22 \%$ & 4733 & $23.33 \%$ & $<0.001$ \\
\hline $\begin{array}{l}\text { Antibiotics during index hospitalization prior to } \\
\text { cUTI Index Day }\end{array}$ & 225 & $7.40 \%$ & 1594 & $7.86 \%$ & 0.384 \\
\hline C3-R organism within 90 days prior to admission & 356 & $11.71 \%$ & 386 & $1.90 \%$ & $<0.001$ \\
\hline FQ-R organism within 90 days prior to admission & 588 & $19.34 \%$ & 1436 & $7.08 \%$ & $<0.001$ \\
\hline TMP/SMZ-R organism within 90 days prior to admission & 495 & $16.28 \%$ & 799 & $3.94 \%$ & $<0.001$ \\
\hline FFM-R organism within 90 days prior to admission & 1 & $0.03 \%$ & 1 & $0.00 \%$ & 0.244 \\
\hline NFT-R organism within 90 days prior to admission & 307 & $10.10 \%$ & 625 & $3.08 \%$ & $<0.001$ \\
\hline TR organism within 90 days prior to admission & 411 & $13.52 \%$ & 327 & $1.61 \%$ & $<0.001$ \\
\hline \multicolumn{6}{|l|}{ Treatment } \\
\hline \multicolumn{6}{|l|}{ Antibiotics administered by day 2 from onset } \\
\hline $\begin{array}{l}\text { Antipseudomonal penicillins with beta-lactamase } \\
\text { inhibitor }\end{array}$ & 1107 & $36.41 \%$ & 6507 & $32.07 \%$ & $<0.001$ \\
\hline Extended spectrum cephalosporins & 1651 & $54.31 \%$ & 13,576 & $66.91 \%$ & $<0.001$ \\
\hline
\end{tabular}


Table 3 Infection and treatment characteristics (Continued)

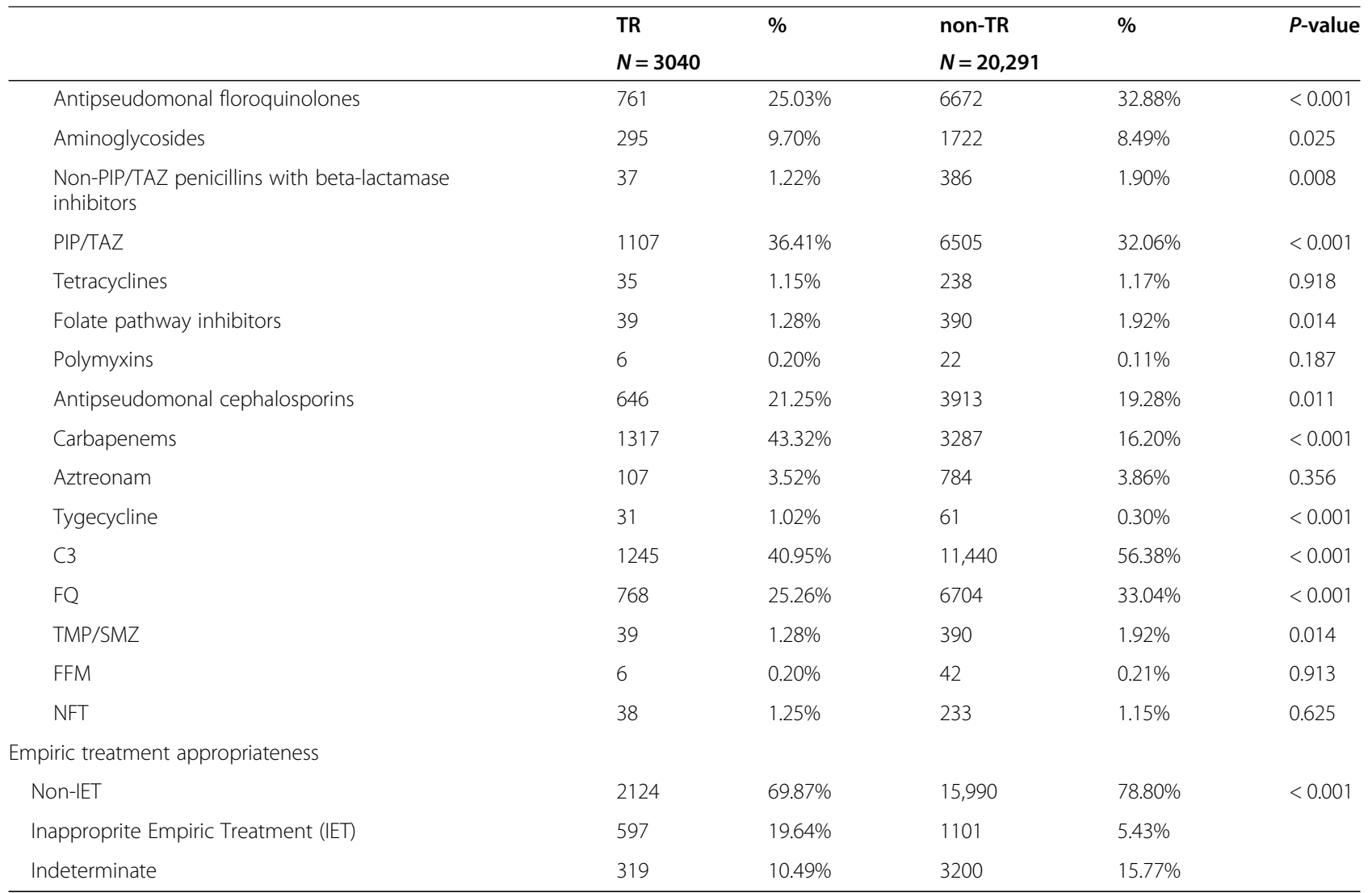

MDR multidrug resistant, SD standard deviation, IQR interquartile range, ICU intensive care unit, $P O A$ present on admission, $C U T I$ complicated urinary tract infection, CAUTI catheter-associated UTI, $R$ resistant, C3 3rd generation cephalosporin, FQ fluoroquinolone, TMP/SMZ trimethoprim-sulfamethoxazole, FFM fofsomycin, NFT nitrofurantoin, $R$ resistant, PIP/TAZ piperacillin-tazobactam, IET inappropriate empiric therapy

classes (Table 3). Despite more frequent use of such broad-spectrum empiric coverage as piperacillin-tazobactam and carbapenems, the group with TR, compared to non-TR, were more likely to receive IET $(19.6 \%$ vs. $5.4 \%, p<0.001)$.

The unadjusted outcomes are depicted in Supplemental Table 3. As for adjusted outcomes, although TR was not associated with a rise in hospital mortality or 30-day readmission rate, it was associated with greater hospital
LOS and costs (Table 4). Testing for interactions revealed that TR affects both LOS and costs differently among patients with CAUTI versus non-CAUTI cUTI. Namely, though the entire cUTI cohort's mean TR-attributable cost excess was $\$ 754$ (95\% CI $\$ 406, \$ 1103, p<0.001)$, it was $\$ 125(95 \%$ CI $-\$ 275, \$ 525, p=0.540)$ for CAUTI and $\$ 1637$ (95\% CI \$1045, \$2229, $p<0.001$ ) for non-CAUTI cUTI (Supplemental Fig. 1). Similarly, though non-

Table 4 Adjusted contribution of triple resistance to outcomes

\begin{tabular}{lllll}
\hline Outcome & Metric & Point estimate & 95\% confidence interval & $P$ value \\
\hline Mortality & Odds ratio & 1.03 & $(0.78,1.35)$ & 0.844 \\
30-day readmission & Odds ratio & 1.04 & $(0.94,1.16)$ & 0.429 \\
Hospital cost & Excess $\$$ & $\$ 754$ & $(\$ 406, \$ 1103)$ & $<0.001$ \\
Total LOS & Excess days & 0.28 days & $(0.12,0.44)$ & $<0.001$ \\
Post-infection onset LOS & Excess days & 0.34 days & $(0.18,0.49)$ & $<0.001$ \\
CDI & Odds ratio & 1.49 & $(0.95,2.32)$ & 0.08 \\
CUTI relapse & Odds ratio & 0.82 & $(0.44,1.54)$ & 0.535 \\
\hline
\end{tabular}

LOS length of stay, CDI C. difficile infection, $C U T I$ complicated urinary tract infection ancident CDI $n=118(0.5 \%)$ 
CAUTI-cUTI patients had a TR-attributable increase in post-infection onset LOS of 0.62 days $(95 \%$ CI $0.35,0.88$, $\mathrm{p}<0.001$ ), CAUTI patients stayed longer regardless of their TR status, driving the overall cohort's LOS excess related to TR to 0.34 days ( $95 \%$ CI $0.18,0.49, p<0.001$ ). The results were similar for the total LOS (data not shown).

Examining the impact of IET on the outcomes of cUTI revealed similar interaction with the type of CUTI in the mortality estimate. That is, in patients with non-CAUTI cUTI, IET raised the risk of mortality (OR 2.44; 95\% CI $1.30,4.56, p=0.005)$, while this effect was absent in the CAUTI group (1.26; 95\% CI 0.77, 2.04, $p=0.355)$. Additionally, IET was associated with increases in marginal hospital costs ( $\$ 1364$ in total costs; $95 \%$ CI $\$ 923, \$ 1805$, $p<0.001$ ), overall LOS (0.66 days; $95 \%$ CI $0.46,0.86, p<$ 0.001 ), and post-infection LOS (0.73 days; $95 \%$ CI 0.52 , $0.94, \mathrm{p}<0.001)$ in the cUTI cohort overall.

Although incident CDI occurred in only $0.5 \%$ of the cohort, TR increased the risk of its occurrence, but did not reach statistical significance (OR 1.49, 95\% CI 0.95 , 2.32, $p=0.08$, Table 4). TR was not associated with an increased risk of cUTI recurrence. Notably, the development of TR was rare in the non-TR group $(0.45 \%$, Supplemental Table 3).

\section{Discussion}

In this large multicenter retrospective analysis of US hospitals TR is present in approximately $13 \%$ of patients with a cUTI. That is, nearly 1 in 8 patients with a cUTI, the vast majority of which are community-onset, are infected with a pathogen that is resistant to at least 3 of the following antimicrobials/classes: 3rd generation cephalosporins, fluoroquinolones, trimethoprim-sulfamethoxazole, fosfomycin, and nitrofurantoin. Not surprisingly, the presence of a TR pathogen increases the risk for IET. Interestingly, both TR and IET impact the outcomes differentially, depending on the type of cUTI. TR and IET are not significantly associated with higher costs or LOS in CAUTI, which are already high in this subset of cUTI. In contrast, non-CAUTI cUTI incur both higher costs and LOS with TR and IET, and higher mortality with IET. Indeed, IET results in an increase in the LOS of nearly 1 day, and excess costs of over $\$ 1300$. TR and IET were important drivers in non-CAUTI cUTI of these outcomes even in the face of overall high severity of illness, with nearly $1 / 4$ requiring ICU, and over $10 \%$ with septic shock. Finally, though its overall incidence was low, CDI was associated more frequently with TR than non-TR, though this difference failed to reach statistical significance likely due to its low incidence.

We have specifically avoided the language of "multidrug resistant" (MDR) in our analysis. The US Centers for Disease Control and Prevention defines as MDR an isolate that is resistant to at least one antibiotic in three or more drug classes [14]. If those classes are not routinely employed as treatment for a specific syndrome, however, the term has little practical application to front line physicians while they make treatment choices. Hence, instead of enumerating the frequency of in vitro non-susceptibility to choices one might never consider in cUTI, our study addressed agents regularly given in this specific setting, so as to identify the characteristics of patients in whom the "standard" regimens might fail.

In contrast to some other populations, where both resistance and IET contribute to a rise in mortality we did not find that to be the case in the overall cUTI cohort [15-18]. This is likely due to the low (2\%) baseline mortality rate compared to infections such as healthcare- and ventilator-associated pneumonia and sepsis, where crude case fatality ranges from 10 to $40 \%$ [11, 12 , 15-22]. This lack of a mortality effect in our study mirrors that in other low-risk of death infections, including severe skin infection [23]. However, we identified a differential effect for both TR and IET on the outcomes, depending on the type of cUTI - CAUTI vs. non-CAUTI cUTI. Namely, while TR and IET alter the outcomes in the latter, they do not appear to have an impact in the former, suggesting that these two groups should be analyzed separately vis-à-vis their treatment outcomes.

The relationship between TR and IET and excess costs in our population is also consistent with the findings of others. Work in multiple other infections, including lower mortality syndromes, regularly illustrates that resistance contributes to IET, and delayed or inappropriate empiric therapy increases the LOS and, in turn, adds to costs [23]. Our findings specific to cUTI are novel and add to the present literature. Importantly, although an absolute increase in LOS of less than one day may appear trivial at first glance, our estimate of IETattributable excess of 0.7 days represents approximately $10 \%$ of the entire LOS for the average patient with a cUTI. Similarly, even though TR- and IET-attributable excess costs of $\$ 754$ and $\$ 1364$, respectively, may seem modest, from a hospital perspective these costs can quickly become substantial, given the combination of frequency of admissions with a cUTI and the already strained reimbursement rates.

One additional novel aspect of our study is that we quantified incident CDI in cUTI. Although the overall rate was lower than in other hospitalized populations, TR did increase the risk of this infection [13, 24-26]. Though we did not specifically examine the implications of CDI on 30-day readmission, it is likely another potential source of LOS and cost rise.

What are the practical implications of our observations? First, certain exposures remain associated with TR. Some of these relate to prior interaction with the healthcare system and suggest that physicians must strive to determine a patient's prior healthcare and 
antibiotic exposures when making prescribing decisions. Though the concept of "healthcare-associated infection" may currently be out of favor in select formal guidelines, the evidence indicates that not all community-onset infections pose the same risk for resistance and the accompanying concern for IET [27]. Second, pre-test probability matters. That is, readers should not interpret our findings as a call to abandon current practices and move to selecting broader-acting antimicrobials for first line therapy in CUTI; that would only serve to foster more resistance. Rather, our observations stress the imperative for physicians to have granular data on local microbiology as a function of the syndromes they treat.

Our study has a number of limitations and strengths. The observational nature of the study predisposes it to multiple threats to validity, particularly a selection bias. By defining the cohort prospectively, we attempted to mitigate the magnitude of this bias. Misclassification is an issue, particularly when using administrative data. To deal with this, we used a previously published, though not clinically validated, algorithm, excluded other potential sources of infection, and included microbiology specimens, pharmacy data, and dates of cultures and treatments to minimize its magnitude. If present, however, this type of misclassification would drive the differences between groups toward null. At the same time, we could not differentiate between infection and colonization. Confounding is a potential problem in all observational studies. We performed multivariable modeling to minimize its impact using many confounders. However, some residual confounding may remain. Because this is a large multicenter geographically representative database, generalizability is of minimal concern, though we must caution that our results apply only to hospitalized patients, and not those treated in the community. Despite these limitations, this is the largest multicenter cohort study to examine the prevalence, time trends and outcomes of antimicrobial resistance in cUTI.

\section{Conclusions}

In summary, we have demonstrated that resistance to combinations of regularly used antimicrobials is prevalent and on the rise in the most common cUTI organisms in the US hospitals. Though increasing resistance alone does not impact hospital mortality, it does expose patients to an elevated risk of worsened outcomes through increasing the likelihood of inappropriate empiric therapy.

\section{Supplementary Information}

The online version contains supplementary material available at https://doi. org/10.1186/s12879-021-05842-0

Additional file 1.

\section{Abbreviations}

CUTI: Complicated urinary tract infection; CAUTI: Catheter-associated urinary tract infection; CO: Community-onset; HO: Hospital-onset; ESBL: Extendedspectrum beta-lactamase; IET: Inappropriate empiric therapy;

HCA: Healthcare-associated; CA: Community-acquired; R: Resistant; C3: 3rd generation cephalosporins; FQ: Fluoroquinolones; TMP-SMZ: Trimethoprimsulfamethoxazole; FFM: Fosfomycin; NTF: Nitrofurantoin; TR: Triple-drug resistant; LOS: Length of stay; CDI: C. difficile infection; IQR: Interquartile range; Cl: Confidence interval; MDR: Multidrug resistant

\section{Acknowledgements}

No one other than the authors contributed to the study or this manuscript.

Financial support

This study was supported by a grant from Spero Therapeutics, Cambridge, MA, USA.

\section{Disclosure}

Data from this study have in part been presented at ID Week 2019.

\section{Authors' contributions}

MDZ, KS, and AFS contributed substantially to the study design, data interpretation, and the writing of the manuscript. BHN had full access to all of the data in the study and takes responsibility for the integrity of the data and the accuracy of the data analysis. He contributed substantially to the study design, data analysis, and the writing of the manuscript. No persons other than the authors participated in the study or the writing of the manuscript. The authors read and approved the final manuscript.

\section{Availability of data and materials}

The data that support the findings of this study are available from Premier Research but restrictions apply to the availability of these data, which were used under license for the current study, and so are not publicly available. Data are however available from the authors upon reasonable request and with permission of Premier Research.

\section{Ethics approval and consent to participate}

Because this study used already existing fully de-identified data, it was exempt from ethics review under US 45 CFR 46.101 (b)4 [8].

Consent for publication

Not applicable.

\section{Competing interests}

- MDZ is a consultant to Spero Therapeutics. Her employer, EviMed Research Group, LLC, has received research grant support from Spero Therapeutics.

- BHN's employer, OptiStatim, LLC, has received support from EviMed Research Group, LLC

- KS is an employee of and stockholder in Spero Therapeutics.

- AFS is a consultant to and has received research grant support from Spero Therapeutics.

- MDZ and AFS have received grant support and/or have served as consultants to Merck, Melinta, Tetraphase, Pfizer, Astellas, Shionogi, The Medicines Company, Lungpacer, and Theravance.

\section{Author details}

${ }^{1}$ EviMed Research Group, LLC, PO Box 303, Goshen, MA 01032, USA. ${ }^{2}$ OptiStatim, LLC, 25 Willow Circle, Longmeadow, MA 01106, USA. ${ }^{3}$ Spero Therapeutics, 675 Massachusetts Avenue, Cambridge, MA 02139, USA. ${ }^{4}$ Washington Hospital Center, 110 Irving Street NW, Washington, DC 20010, USA.

Received: 30 October 2019 Accepted: 26 January 2021

Published online: 08 February 2021

References

1. Hospital Compare. Medicare.gov: The Official US Government Site for Medicare. Available at https://www.medicare.gov/hospitalcompare/Data/Da ta-Updated.htm|\#. Accessed 31 May 2019. 
2. Saint S, Meddings JA, Calfree D, Kowalski CP, Krein SL. Catheter-associated urinary tract infection and the Medicare rule changes. Ann Int Med. 2009; 150:877-84.

3. Sievert DM, Ricks P, Edwards JR, Schneider A, Patel J, Srinivasan A, et al. National Healthcare Safety Network (NHSN) team and participating NHSN facilities. Antimicrobial-resistant pathogens associated with healthcareassociated infections: summary of data reported to the National Healthcare Safety Network at the Centers for Disease Control and Prevention, 20092010. Infect Control Hosp Epidemiol. 2013;34(1):1-14.

4. Zilberberg MD, Shorr AF. Secular trends in gram-negative resistance among urinary tract infection hospitalizations in the United States, 2000-2009. Infect Control Hosp Epidemiol. 2013;34:940-6.

5. Zhanel GG, Hisanaga TL, Laing NM, DeCorby MR, Nichol KA, Weshnoweski B, NAUTICA Group. Antibiotic resistance in Escherichia coli outpatient urinary isolates: final results from the north American urinary tract infection collaborative Alliance (NAUTICA). Int J Antimicrob Agents. 2006;27:468-75

6. Sanchez GV, Master RN, Karlowsky JA, Bordon JM. In vitro antimicrobial resistance of urinary Escherichia coli isolates among U.S. outpatients from 2000 to 2010. Antimicrob Agents Chemother. 2012;56:2181-3.

7. Dalhoff A. Global fluoroquinolone resistance epidemiology and implications for clinical use. Interdiscip Perspect Infect Dis. 2012;2012:976273.

8. US Department of Health and Human Services Office for Human Research Protections. Human Subject Regulations Decision Charts. Available at https://www.hhs.gov/ohrp/regulations-and-policy/decision-charts/index. html; Accessed July 19, 2019.

9. Zilberberg MD, Nathanson BH, Sulham K, Shorr AF. Antimicrobial Susceptibility and Cross-Resistance Patterns among Common Complicated Urinary Tract Infections in U.S. Hospitals, 2013 to 2018. Antimicrob Agents Chemother. 2020;64(8):e00346-20. https://doi.org/10.1128/AAC.00346-20.

10. Zilberberg MD, Nathanson BH, Sulham K, Fan W, Shorr AF. Development and validation of a bedside instrument to predict carbapenem resistance among gram-negative pathogens in complicated urinary tract infections. Infect Control Hosp Epidemiol. 2018;39:1112-4.

11. Rothberg MB, Pekow PS, Priya A, Zilberberg MD, Belforti R, Skiest D, et al. Using highly detailed administrative data to predict pneumonia mortality. PLoS One. 2014;9(1):e87382.

12. Rothberg MB, Haessler S, Lagu T, Lindenauer PK, Pekow PS, Priya A, et al. Outcomes of patients with healthcare-associated pneumonia: worse disease or sicker patients? Infect Control Hosp Epidemiol. 2014; 35(Suppl 3):S107-15.

13. Lagu T, Stefan MS, Haessler S, Higgins TL, Rothberg MB, Nathanson BH, Hannon NS, Steingrub JS, Lindenauer PK. The impact of hospital-onset Clostridium difficile infection on outcomes of hospitalized patients with sepsis. J Hosp Med. 2014:9:411-7.

14. Magiorakos AP, Srinivasan A, Carey RB, et al. Multidrug-resistant, extensively drug-resistant and pandrug-resistant bacteria: an international expert proposal for interim standard definitions for acquired resistance. Clin Microbiol Infect. 2012;18:268-81.

15. Iregui M, Ward S, Sherman G, et al. Clinical importance of delays in the initiation of appropriate antibiotic treatment for ventilator-associated pneumonia. Chest. 2002;122:262-8.

16. Zilberberg MD, Shorr AF, Micek MT, Mody SH, Kollef MH. Antimicrobial therapy escalation and hospital mortality among patients with HCAP: a single center experience. Chest. 2008;134:963-8.

17. Micek ST, Kollef KE, Reichley RM, et al. Health care-associated pneumonia and community-acquired pneumonia: a single-center experience. Antimicrob Agents Chemother. 2007;51:3568-73.

18. Shorr AF, Micek ST, Welch EC, Doherty JA, Reichley RM, Kollef MH Inappropriate antibiotic therapy in gram-negative sepsis increases hospital length of stay. Crit Care Med. 2011:39:46-51.

19. Safdar N, Dezfulian C, Collard HR, Saint S. Clinical and economic consequences of ventilator-associated pneumonia: a systematic review. Crit Care Med. 2005;33(10):2184-93.

20. Warren DK, Shukla SJ, Olsen MA, Kollef MH, Hollenbeak CS, Cox MJ, et al Outcome and attributable cost of ventilator-associated pneumonia among intensive care unit patients in a suburban medical center. Crit Care Med. 2003;31(5):1312-7.

21. Rello J, Ollendorf DA, Oster G, Vera-Llonch M, Bellm L, Redman R, et al. VAP outcomes scientific advisory group. Epidemiology and outcomes of ventilator-associated pneumonia in a large US database. Chest. 2002; 122(6):2115-21.

22. Restrepo MI, Anzueto A, Arroliga AC, Afessa B, Atkinson MJ, Ho NJ, et al. Economic burden of ventilator-associated pneumonia based on Total resource utilization. Infect Control Hosp Epidemiol. 2010;31(5):509-15.

23. Zilberberg MD, Shorr AF, Micek ST, Hoban AP, Pham V, Doherty JA, Ramsey AM, Kollef MH. Epidemiology and outcomes of hospitalizations with complicated skin and skin structure infections: implications of healthcare associated infection risk factors. Infect Control Hosp Epidemiol. 2009;30: 1203-10.

24. Zilberberg MD, Nathanson BH, Sadigov S, Higgins TL, Kollef MH, Shorr AF. Epidemiology and outcomes of Clostridium difficile-associated disease among patients on prolonged acute mechanical ventilation. Chest. 2009; 136:752-8.

25. Chalmers JD, Akram AR, Singanayagam A, Wilcox MH, Hill AT. Risk factors for Clostridium difficile infection in hospitalized patients with communityacquired pneumonia. J Inf Secur. 2016;73:45-53.

26. Carrabba M, Zarantonello M, Formica S, Mellace L, Castaldi S, Cappellini MD, Fabio G. Pneumonia and Clostridium difficile infection: hospital acquired infection in a non-ICU department. Eur Respir J. 2012:40:P2469.

27. Kalil AC, Metersky ML, Klompas M, Muscedere J, Sweeney DA, Palmer LB, et al. Management of Adults with Hospital-acquired and Ventilatorassociated Pneumonia: 2016 clinical practice guidelines by the Infectious Diseases Society of America and the American Thoracic Society. Clin Infect Dis. 2016;63(5):e61-e111.

\section{Publisher's Note}

Springer Nature remains neutral with regard to jurisdictional claims in published maps and institutional affiliations.

\section{Ready to submit your research? Choose BMC and benefit from:}

- fast, convenient online submission

- thorough peer review by experienced researchers in your field

- rapid publication on acceptance

- support for research data, including large and complex data types

- gold Open Access which fosters wider collaboration and increased citations

- maximum visibility for your research: over $100 \mathrm{M}$ website views per year

At $\mathrm{BMC}$, research is always in progress.

Learn more biomedcentral.com/submissions 